\title{
Determinação do início da precipitação de materiais através de técnicas de aprisionamento ótico
}

René Alfonso Nome Silva (PQ), Bruno Fedosse Zornio (PG), Maria Rodrigues Pinto (IC)

\section{Resumo}

Caracterizar as condições termodinâmicas de uma solução antes que essa inicie a precipitação é de fundamental importância caso a precipitação seja um empecilho no sistema. Através da microscopia é possível determinar, por exemplo, como o coeficiente de difusão das partículas varia com a concentração da solução.

Palavras Chave: precipitação, espectroscopia, pinça ótica

\section{Introdução}

Caracterizar as propriedades do sistema quando se principia a precipitação é de fundamental importância para o controle das condições do sistema, visto que em alguns casos ela pode interferir um processo e deve ser evitada. Isto está diretamente relacionado ao equilíbrio de sistemas. Para caracterizarmos a dinâmica de precipitação a nível molecular é necessário utilizar técnicas microscópicas. Quando em solução, as partículas, movimentam-se de forma aleatória devido à energia térmica do sistema. Desse modo, iremos sempre observar um movimento aleatório das moléculas, também chamado de Movimento Browniano. O aprisionamento ótico através do uso da Pinça ótica é de interesse já que o ponto de aprisionamento, o foco do laser, pode funcionar como um ponto de nucleação, desse modo, a partir do uso da pinça ótica é possível estudar a dinâmica de precipitação de uma solução.

\section{Resultados e Discussão}

O coeficiente de difusão é calculado a partir da trajetória das partículas numa certa faixa de tempo. Onde, o experimento foi repetido diversas vezes, de modo a controlar as variáveis do sistema, com 0 objetivo de minimizarmos qualquer influência externa. Para concentrações altas, bem próximas a agregação máxima das micropartículas, obtemos o seguinte padrão observado no Gráfico 1. As partículas tendem a ter um coeficiente de difusão um mínimo ao se aproximarem da concentração necessária para se iniciar a aglomeração e assim, precipitação.

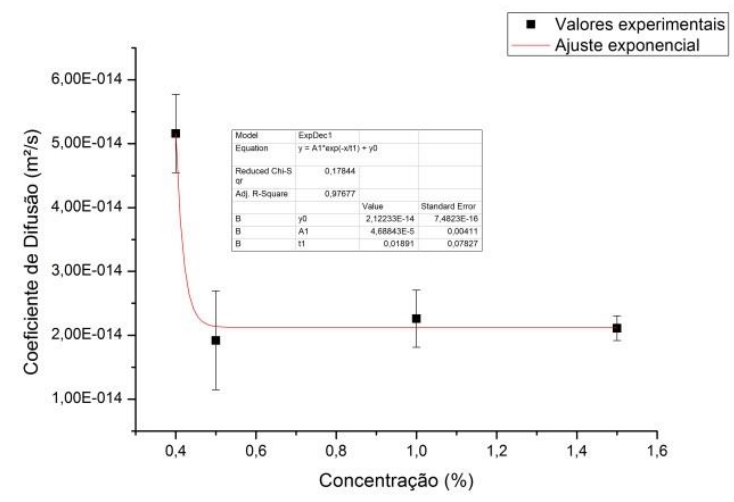

Figura 1. Coeficiente de difusão pela concentração

\section{Conclusões}

Através das atividades realizadas podemos observar que existe, de fato, uma relação entre o coeficiente de difusão do poliestireno, uma micropartícula, e a concentração da solução de trabalho. Os resultados obtidos através do programa ImageJ e as análises posteriores feitas com o dados no MatLab são eficientes em nos fornecer os valores dos coeficientes, embora haja uma discrepância muito grande entre os valores obtidos, que não foi possível observar a causa exata, para poder assim reduzir os desvios, embora tenham sido realizados uma série de ajustes.

\section{Agradecimentos}

Sou grata pela oportunidade dada pelo professor René Nome, pela ajuda frequente do Bruno Zornio, e também de todos os demais do laboratório e pelo apoio de todos os meus amigos e família.

\footnotetext{
${ }^{1}$ Catipovic, M. A. et al. Improving the quantification of Brownian motion. American Journal of Physics, v. 81, n. 7, p. 485-491, 2013.

${ }^{2}$ Zornio, B. F. Estudo teórico e experimental da teoria de Kramers utilizando pinças ópticas e dinâmica de Langevin 2014
} 